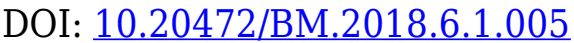

\title{
THE IMPORTANCE OF INTEGRATING QUANTITATIVE RESEARCH METHODS TO UNDERSTAND COMMODITY BUSINESS FINANCE
}

\author{
MIROSLAVA ZAVADSKA, LUCÍA MORALES, JOSEPH COUGHLAN, LUCÍA \\ MORALES, JOSEPH COUGHLAN
}

\begin{abstract}
:
There is significant array of quantitative methods used to analyse the basic properties and behaviour of commodity markets. This study focuses on how integrating these methods can aid our understanding of how crude oil markets behave during major shock events that exhibit high levels of uncertainty and risk exposure to businesses that rely on commodities to function. The study considers the relationship and behaviour of spot prices of major oil benchmarks: Brent crude oil (the European crude oil benchmark), the West Texas Intermediate (the US benchmark) and the Dubai crude oil (the Middle East benchmark). The research framework under consideration can bring value to businesses, and practitioners, as it offers opportunities to identify, and measure, how oil prices variations impact on the costs of business operations. A clearer understanding of oil price dynamics aids the decision maker with complex decisions such as strategic investment and sourcing of raw materials. These issues can be quantified and then integrated into operational plans, and hedging strategies can be implemented to minimise risk exposure to oil market fluctuations. Through the implementation of an integrated battery of research methodologies commonly used to model oil prices, this paper contributes towards the operationalisation of econometric modelling in business. This study considers that markets are not as predictable as it was once thought, and decisions are, in reality, made based on how we, as humans, think and engage with the organisational environment. Financial models and theories can offer support to practitioners when measuring cost implications for their businesses.
\end{abstract}

\section{Keywords:}

Business finance, Multi method research, Commodity, Energy, Shock periods, Cointegration, Causality, Volatility, Efficiency, Decision-making.

JEL Classification: E37, G01, Q47

\section{Authors:}

MIROSLAVA ZAVADSKA, Dublin Institute of Technology, Ireland, Email:

miroslava.zavadska@student.dit.ie

LUCÍA MORALES, Dublin Institute of Technology, Ireland, Email: lucia.morales@dit.ie JOSEPH COUGHLAN, Maynooth University, Ireland, Email: joseph.coughlan@nuim.ie LUCÍA MORALES, Dublin Institute of Technology, Ireland, Email: lucia.morales@dit.ie JOSEPH COUGHLAN, Maynooth University, Ireland, Email: joseph.coughlan@nuim.ie 


\section{Citation:}

MIROSLAVA ZAVADSKA, LUCÍA MORALES, JOSEPH COUGHLAN, LUCÍA MORALES, JOSEPH COUGHLAN (2018). The Importance of Integrating Quantitative Research Methods to Understand Commodity Business Finance. International Journal of Business and Management, Vol. VI(1), pp. 54-77., 10.20472/BM.2018.6.1.005 


\section{Introduction}

Researchers, scholars, practitioners and scientists follow qualitative, quantitative or mixed research methodologies to find answers to their research questions. In the context of business management studies, researchers tend to choose their approach by examining the research problem of interest and by contrasting and analysing existing research practices. In this way, researchers can both question and further analyse existing research methodologies and how they can be used to support businesses in their decision-making process. However, the link between scholars and practitioners is an area that requires further study to aid the connection between scholarly practice and the needs and demands of businesses. By looking at commodity business finance, and more specifically the analysis of oil markets, it is possible to identify a significant variety of research methods that are used in the field. However, it is not very clear in which way existing financial models can be used by practitioners to support their businesses and how they can be used to aid their practices in a meaningful manner. Thus, this study has two main contributions: a) an analysis and critical assessment of how researchers and analysts have studied the dynamics of oil markets, and b) identification of econometric models that are commonly used in the field, to determine how they can be implemented in the business context. The remainder of the paper is organised as follows: a brief overview of the extant literature on commonplace research methods used to model oil prices behaviour. The analysis continues with the presentation of relevant research methods selected to support the empirical side of the study. The study progresses with the examination of market efficiency from the traditional/classical standpoint, and how market efficiency concepts can be considered in the business context. A worked example on the analysis of oil prices around the period of the Global Financial Crisis is presented. The final section provide a critical discussion of the implemented research methodologies and how they can be used to support the business decision process, and finally the paper concludes.

\section{$2 \quad$ Literature Review}

The analysis of commodity markets, and especially crude oil markets as the world's main energy source, plays an important part in studies of business finance. Research looking at oil dependent industries is relevant because oil represents a significant cost to businesses in sectors such as airlines, road and rail transport and the pharmaceutical industries which need to understand the dynamics of oil markets. Researchers typically use a variety of research methodologies to examine the dynamics of crude oil markets. For example, the use of historical and the most up to date information permit the identification of market trends and the development of projections that help to minimise risk-taking positions. Researchers such as Bekiros and Diks (2008), Charles and Darné (2009), Charles et al., (2011), Narayan et al., (2013), Mensi et al., (2014), Bouri (2015) and others show that the use of historical data contributes towards a a basic understanding of market dynamics, offers more robust results, and provides a comprehensive picture of crude oil commodity market behaviour. For example, the analysis of long and/or short-term relationship between crude oil prices can help to understand the co-movements of the prices for different oil indexes or benchmarks. This type of analysis can indicate the existence of possible lead-lag relationships between oil prices that can help businesses to plan potential hedging strategies against adverse oil price fluctuations (Silvapulle and Moosa, 1999; Bekiros and Diks, 2008; Mamatzakis and Remoundos, 2011; Zhang and Wang, 2013; Ding et al., 2014). Researchers have also devoted attention to the 
study of the volatility of crude oil markets. This research stream considers how market uncertainty and risk fears about the future of oil price levels can spill over to the real economy and can impact on business activities (Sadorsky, 2012; Salisu and Fasanya, 2013; Charles and Darné, 2014; Wang et al., 2016). Another line of research has considered the oil market under the Efficient Market Hypothesis (Fama, 1965). This research helps to identify if there are predictable patterns in oil prices, and whether or not there could be indicators affecting oil prices, that could be of use to businesses, governments, economists and analysts when developing their strategic planning and decision-making processes. Some recent examples of studies in this area include Lean et al., (2010), Khediri and Charfeddine (2015) and Gu and Zhang (2016), who offer evidence that demonstrates the importance of analysing oil markets and its changing patterns over time, which have implications for investment strategies.

Structural break analysis is also a relevant part in the analysis of crude oil markets, as testing for unexpected changes in oil price behaviour can disrupt econometric models resulting in spurious outcomes that can lead towards wrong interpretation of market behaviour. For example, Lee et al., (2010) and Mensi et al., (2014) pointed out that the inclusion of structural breaks in econometric modelling helps to avoid misspecified outcomes. Key methodologies that can be applied in the study of crude oil prices, and indeed other commodities, include multiple structural breaks such as the Bai-Perron structural break test (Bai and Perron, 1988), recently applied by Mensi et al., (2014). The long term and short term relationship tests represented by the Johansen cointegration test, the Engle-Granger cointegration test, Granger causality tests and VECM models (Bekiros and Diks, 2008; Zhang and Wang, 2013; Ding et al., 2014) are also frequently applied. A set of volatility models using the GARCH type models (Sadorsky, 2012; Salisu and Fasanya, 2013; Charles and Darné, 2014) and efficiency testing examining the random walk hypothesis through variance ratio tests (Khediri and Charfeddine, 2015; Gu and Zhang, 2016) are also popular approaches. These approaches are used to understand the dynamics of crude oil markets and their connections to the real economy. This study focuses on the application of these methods to demonstrate the need to integrate techniques in the research on oil price dynamics when developing insights for business.

\section{Research Framework}

The modelling of oil prices starts with the basic analysis of time series properties to ensure feasibility of the modelling approach. After that, the mean equation is constructed based on the tested variables. The selected dataset for the quantitative testing typically consists of daily closing spot prices for the main crude oil markets to offer consistency, capture daily oil price jumps and include enough observations for econometric modelling. Studies also use monthly data and more high frequency data is becoming more available.

The mean equations to be considered are outlined below:

$$
\begin{aligned}
& S_{y t}=\beta_{0}+\beta_{1} * S_{i t}+\beta_{2} * S_{i t-1}+\ldots+\beta_{n} * S_{i t-n}+\varepsilon_{t} \\
& S_{i t}=\beta_{0}+\beta_{1} * S_{y t}+\beta_{1} * S_{y t-2}+\cdots+\beta_{n} * S_{y t-n}+\varepsilon_{t}
\end{aligned}
$$

Where $S_{y t}$ refers to oil spot price of variable y; $S_{i t}$ is oil spot price of variable i; $\varepsilon$ denotes the Error Term; and $t$ is Time Series Daily Data. 
The typical process for a study of this nature is as follows. The quantitative methodology is supported by stationarity analysis, where the well-known Augmented Dickey-Fuller test (ADF) is applied (Dickey and Fuller, 1979). Subsequently, structural breaks, cointegration, causality, volatility and efficiency tests are implemented. These methodologies were selected in line with the extant literature (Bekiros and Diks 2008; Zhang and Wang 2013; Ding et al., 2014) that focuses on the analysis of the relationship and dynamics between oil prices. It is important to identify suitable research methodologies that fit our data, which can explain commodity performance and critically analyse unexpected trends. Figure 1 indicates the steps taken in this paper.

Figure 1: Methodology Chart

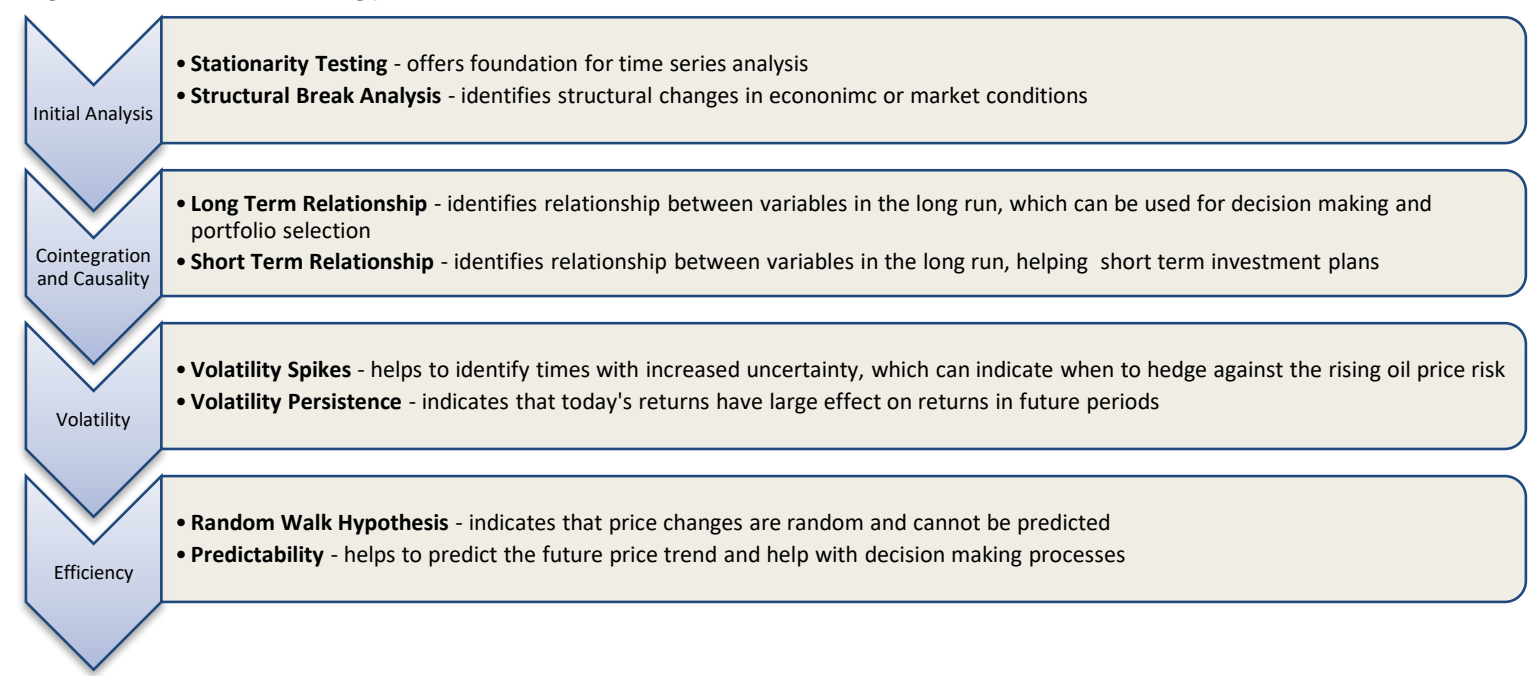

The initial analysis of stationarity and structural breaks offer an important foundation for further examination and the identification of structural changes of tested time series. The long term and short-term tests are conducted to offer insights of the relationship between variables to indicate dynamics for specific time periods. Volatility, which is associated with uncertainty in the market, analyses two issues: spikes and persistence, both of which are important for decision-making processes related to oil price levels and market changes. Lastly, the analysis of efficiency considers at the predictability of the oil market, which indicates whether the oil prices are random or if they show any patterns based on their past behavior, which helps with strategic plans and investment decisions. The use of a combination of tests highlights the dynamics inherent in oil prices, and offers indicators for business practitioners regarding investment and strategic plans by highlighting patterns and dynamics for specific time periods. The remainder of this section goes through the details of these methods.

\subsection{Stationarity and Structural Breaks}

The stationarity of time series data is the first test conducted in the analysis. This test establishes if the dataset has a unit root, which tests if it is a non-stationary process. In other words, stationarity means that the time series moves around its mean value. Non-stationary data cannot be used in econometric testing as the results of tests cannot be relied on. A widely used stationarity test (Zivot and Andrews, 1992; Sadorsky, 1999; Bekiros and Diks, 2008; Robe and Wallen, 2016) is the Augmented Dickey-Fuller test (Dickey and Fuller, 1979). To identify 
structural break points, a variety of models can be used. Structural break points are unexpected shifts in oil price behavior that need to be included in the analysis to avoid spurious results. To identify the existence of such breakpoints, typical tests include the Chow test, the QuandtAndrews test and the Bai-Perron test. These tests were selected based on existing literature (Hansen, 2001; Bekiros and Diks, 2008; Mensi et al., 2014 and others) and have been found to work well when studying commodity markets. The main differences between the tests are that the Chow and Quandt tests can identify only a single break point. In the case of Chow test, we look at specific date and a break point is either found or not recognised. The Quandt test can find a break point from the series. The Bai-Perron test has the ability to find multiple breaks in the data set. This identifies structural changes in the time series which then can be connected to specific events. Structural breaks can help businesses with strategies and planning by identifying dynamics and patterns in certain periods.

To identify the particular break points for the series, typically the Chow test (Chow 1960) is first applied. It consists of breaking the sample into two or more structures, on a specific date, and its equation is:

$$
F=\frac{\left(S S R_{n}-\left(S S R_{n_{1}}+S S R_{n_{2}}\right)\right) / k}{\left(S S R_{n_{1}}+S S R_{n_{2}}\right) /\left(n_{1}+n_{2}+2 k\right)}
$$

where $S S R_{n}$ is combined regression line, $S S R_{n_{1}}$ is the regression line before the break and $S S R_{n_{2}}$ is the regression line after the break.

The Quandt-Andrews test is an extension to the Chow test and it is used in situations where the break-date is unknown (Hansen 2001). Quandt (1960) proposed taking the largest Chow statistic over all possible break-dates which essentially is the likelihood test under normality. On the other hand, the Bai-Perron test is capable of identifying multiple structural breaks. This test examines the break points between multiple variables simultaneously. The recommended number of break points is five as more breaks could lead towards problems in terms of testing, as they will condition the number of observations available for study (Mensi et al., 2014). Bai and Perron's (1998) main framework of analysis can be described by the following multiple linear regression with $m$ breaks (or $m+1$ regimes):

$$
y_{t}=x_{t}^{\prime} \beta+z_{t}^{\prime} \delta_{j}+\mu_{t} \quad ; t=T_{j-1}+1, \ldots, T_{j}
$$

for $\mathrm{j}=1, \ldots, m+1$. In this model, $y_{t}$ is the observed dependent variable at time $t$, both for $x_{t}(\mathrm{p} \mathrm{x}$ 1) and $z_{t}(q \times 1)$ are vectors of covariates and $\beta$ and $\delta_{j}(j=1, \ldots, m+1)$ are the corresponding vectors of coefficients; $\mu_{t}$ is the disturbance at time $t$. Break points are explicitly treated as unknown; $T_{0}=0$ and $T_{m+1}=T$ is used. The objective is to estimate the unknown regression coefficients together with the break points when $T$ observations on $y_{t}, x_{t}, z_{t}$ are available. This is a partial change model since the parameter vector $\beta$ is not subject to shifts and is estimated using the entire sample (Bai and Perron 2003). A combination of tests is used to ensure that the changes in the data series are robust to the implementation of different methods. While further methodologies exist, the outcomes of the three tests explained here are usually quite consistent, thus obviating the need for further testing in this regard. 


\subsection{Cointegration}

Cointegration techniques are used to investigate the presence of a long-term relationship between variables. This means that if there is more than one variable, there are tests available to examine if they influence each other, and to identify which of those variables may be leading the other variables. This can be used in recognizing a leading price, which would set a trend for the lagging price. This can simplify the decision-making process when having multiple stocks or shares in a portfolio, which have the long-term relationship established. The selected research methodology offers insights into the kind of relationship that characterizes oil prices by comparing the outcomes. In the case of this paper, spot and future prices can be used to see if they have a long-term relationship. The Johansen cointegration test (Johansen 1988) can be applied in combination with the Engle and Granger (1987) approach, thus permitting cross checking of the results and identifying if the outcomes from both tests are consistent. This reliance on more than one test gives more certainty to the outcomes. The Johansen (1988) approach extends the single equation error correction model to a multivariate one. Let's assume that there are three endogenous variables $y_{t}, x_{t}$ and $w_{t}$ and the matrix notation is $Z_{t}=$ $\left[y_{t}, x_{t}, w_{t}\right]$

$$
Z_{t}=A_{1} Z_{t-1}+A_{2} Z_{t-2}+\cdots+A_{k} Z_{t-k}+\mu_{t}
$$

The above equation is equivalent to the single equation dynamic model for two variables $y_{t}$ and $x_{t}$. It can be reformulated in a vector error correction model (VECM) as:

$$
\Delta Z_{t}=\Gamma_{1} \Delta Z_{t-1}+\Gamma_{2} \Delta Z_{t-2}+\cdots+\Gamma_{k-1} \Delta Z_{t-k-1}+\Pi Z_{t-1}+\mu_{t}
$$

where $\Gamma_{i}=\left(I-A_{1}-A_{2}-\cdots-A_{k}\right)(\mathrm{i}=1,2, \ldots, k-1)$ and $\Pi=-\left(I-A_{1}-A_{2}-\cdots-A_{k}\right)$.

The VECM model includes the Error Correction Term (ECM) that corrects causality analysis in cases of cointegration. Alternative methodologies are available, however these two models are commonly used to test for cointegration as they offer robust results.

\subsection{Causality}

Causality testing is about understanding short-term relationships. The specific research method under consideration was chosen based on the reviewed literature (Bekiros and Diks, 2008; Wang and Wu, 2013; Ding et al., 2014; Mehrara and Hamldar, 2014). Causality modelling is used to identify short term relationships and their direction of influence by looking at short run movements on a continuous basis. This is of interest when looking at oil price dynamics during different periods as it can offer insights for businesses during various economic, political or business cycles. The well-established Granger Causality test (Granger 1969) was implemented, where two stationary variables are regressed against each other in two separate equations.

$$
\begin{aligned}
& y_{t}=\alpha_{1}+\sum_{i=1}^{n} \beta_{i} x_{t-i}+\sum_{j=1}^{m} \gamma_{j} y_{t-j}+\varepsilon_{1 t} \\
& x_{t}=\alpha_{2}+\sum_{i=1}^{n} \theta_{i} x_{t-i}+\sum_{j=1}^{m} \delta_{j} y_{t-j}+\varepsilon_{2 t}
\end{aligned}
$$

where $y_{t}$ is a dependent variable and $x_{t}$ is an independent variable regressed against $y_{t}$. 
In the case of Brent Crude oil spot and futures prices, Zhang and Wang (2013) identified that at some points in time spot prices cause futures prices. The presented research methodology was carefully selected to ensure that the long and short run relationship between the series under study were properly analyzed and consistent with econometric techniques available and commonly used by researchers in the field and that aligned with extant the extant literature (Bekiros and Diks 2008; Lee and Zeng 2011; Mamatzakis and Remoundos 2011; Candelon et al 2013; Wang and Wu 2013; Ding et al 2014). Where the variables are found to be cointegrated then the VECM model presented in equation (6) is applied. This model includes the Error Correction term (ECM), which corrects the Granger causality test in the presence of long run relationships, otherwise the testing would be mis-specified.

The combination of the chosen methodologies bring value to practitioners and academics in understanding the relationship between oil prices in different periods as the findings could point towards interesting outcomes in terms of a lead-lag relationship between oil prices, especially when the series are affected by shocks or in the presence of structural breaks.

\subsection{Volatility}

Volatility forecasts are used to predict price returns and identify significant changes in oil price behaviour. The GARCH type models are applied in this analysis as they offer the most successful outcomes for volatility modelling for financial data. This is an important issue for businesses, investors and speculators as it could suggest and help to forecast future trends. The well-known Generalised Autoregressive Conditional Heteroskedasticity (GARCH) model presented by Bollerslev (1986) is used in this study. This method is preferred by financial modelling professionals for its simplicity in volatility modelling. The Threshold GARCH (TGARCH) model by Zakoian (1994) is also included as it can capture asymmetries. Firstly, the ARCH model presented by Engle (1982) suggests that the variance of the residuals at time $t$ depends on the squared error term from past periods. The ARCH (q) model specification is presented in equations 9 and 10 below:

$y_{t}=\alpha+\beta^{\prime} x_{t}+\varepsilon_{t}$

where, $\varepsilon_{t} \mid \Omega_{t} \sim$ iid $N\left(0, h_{t}\right)$,

and

$h_{t}=\gamma_{0}+\sum_{j=1}^{q} \gamma_{j} \varepsilon_{t-j}^{2}$

The generalised ARCH model by Bollerslev (1986) known as GARCH (p, q) is outlined as follows:

$y_{t}=\alpha+\beta^{\prime} x_{t}+\varepsilon_{t}$

where, $\varepsilon_{t} \mid \Omega_{t} \sim$ iid $N\left(0, h_{t}\right)$,

and

$h_{t}=\omega+\sum_{i=1}^{p} \alpha_{i} h_{t-i}+\sum_{j=1}^{q} \gamma_{j \varepsilon_{t-j}^{2}}$

Equation (12) states that the value of the variance scaling parameter now depends both on past values of the shocks, which are captured by the lagged squared residual terms, and on the past values of itself, which are captured by lagged terms. The simplest form of $\mathrm{GARCH}(p, q)$ model is the $\operatorname{GARCH}(1,1)$, which is commonly used by many researchers in oil markets, as it generally 
performs better than higher order GARCH models (Lee et al., 2006; Narayan and Narayan 2007; Salisu and Fasanya 2013), for which the variance equation is:

$$
h_{t}=\omega+\alpha \varepsilon_{t-1}^{2}+\beta h_{t-1}
$$

The ARCH and the GARCH models are symmetric; however, it has been observed that negative shocks have larger impact on volatility than positive shocks in most financial time series such as stocks and commodities. Therefore, to test for asymmetries in the conditional variance the T-GARCH model is considered appropriate and therefore it is included as part of this study. The specification of the conditional variance equation for T-GARCH $(1,1)$ is given by:

$h_{t}=\omega+\alpha \varepsilon_{t-1}^{2}+\theta \varepsilon_{t-1}^{2} d_{t-1}+\beta h_{t-1}$

where, $d_{t}$ takes the value of 1 for $\varepsilon_{t}<0$, and 0 otherwise. This means that positive and negative shocks have different impacts. Positive news has an impact of $\alpha$, whereas negative shocks have an impact of $\alpha+\theta$.

The volatility outcomes from the GARCH and TGARCH models show the spikes, persistence and asymmetries of oil price returns and capture the differences when applied to different subperiods.

\subsection{Classic Market Efficiency Framework}

The methods for analysing market efficiency are typically based on the Efficient Market Hypothesis theory (Fama 1965), where the main idea of this concept is based on the Random Walk hypothesis, which is considered as the weak form of EMH. It states that future prices should not be predicted by past price behaviour. Based on this theory, the Variance Ratio (VR) tests are widely used for efficiency testing (Liu and He 1991; Hoque et al., 2007; Charles and Darné, 2009). Firstly, the conventional Lo and MacKinlay (1988) VR test is explained, and then the application of the Chow-Denning (1993), Wright (2000) and the more recent wild bootstrapping by Kim (2006) are discussed. Also, details of wild bootstrapping using GARCH residuals models are discussed as they represent a further advance on the methods.

The importance of oil market efficiency offers interesting insights to oil market practitioners by looking at the predictability or the randomness of oil prices. Moreover, it indicates if the tested variables can be predicted over time or if they are exhibiting random patterns. This can be used for strategic and investment decisions by oil dependent businesses and industries.

\subsubsection{Variance Ratio Tests}

\subsubsection{Lo and MacKinlay (1988 and 1989)}

Lo and MacKinley $(1988 ; 1989)$ first introduced the VR test for efficiency testing. They proposed a test statistic under homoscedasticity ${ }^{1}$ and also under heteroskedasticity ${ }^{2}$. Oil price data, the focus of this paper, typically show evidence of heteroskedasticity, so we perform the test under

\footnotetext{
${ }^{1}$ Homoscedasticity is an assumption that the variance around a regression line is the same for all values of predictor variable (the variance of the errors should be constant).

${ }^{2}$ Heteroscedasticity is present when the size of the error term differs across values of an independent variable (the dataset is not homoscedastic).
} 
this assumption. In other words, it means that the variability of a variable is unequal across the range of values of a second variable that predicts it and we have to take that into account when modelling our data.

Firstly, we specify our regression by $P_{t}$ being the spot price of Brent, WTI or Dubai crude oil daily price at the time $t$ and define $X_{t}=\ln P_{t}$ as the log price process. The regression is as follows:

$X_{t}=\mu+X_{t-1}+\varepsilon_{t}$

where $\mu$ is the arbitrary drift parameter and $\varepsilon_{t}$ is the random disturbance term. Since financial data exhibit changing volatilities over time, therefore the specification test of random walk model must be robust to changing variances. If the oil price follows a random walk or martingale then the price return is unpredictable from the past price information. Following Wright (2000), the VR test can be written as:

$V R(x ; k)=\left\{\frac{1}{T k} \sum_{t=k}^{T}\left(x_{t}+x_{t-1}+\cdots+x_{t-k+1}-k \hat{\mu}\right)^{2}\right\} \div\left\{\frac{1}{T} \sum_{t=1}^{T}\left(x_{t}-\hat{\mu}\right)^{2}\right\}$

where $\hat{\mu}=\frac{1}{T} \sum_{t=1}^{T} x_{t}$. This is an estimator for the unknown population VR, denoted as $V(k)$, which is the ratio of $1 / k$ times the variance of the $k$-period returns to the variance of the oneperiod return. Lo and MacKinlay (1988) showed that if $x_{t}$ is independent and identically distributed (iid), then under the null hypothesis that $V(k)=1$,

$M_{1}(x ; k)=(V R(x ; k)-1)\left(\frac{2(2 k-1)(k-1)}{3 k T}\right)^{-1 / 2}$

follows the standard normal distribution asymptotically. To allow for $x_{t}$ 's showing conditional heteroskedasticity, Lo and MacKinlay (1988) proposed a test statistic that is robust for heteroskedasticity,

$M_{2}(x ; k)=(V R(x ; k)-1)\left(\sum_{j=1}^{k-1}\left[\frac{2(2 k-j)}{k}\right]^{2} \delta_{j}\right)^{-1 / 2}$

which follows the standard normal distribution asymptotically under null hypothesis that $V(k)=$ 1, where,

$\delta_{j}=\left\{\sum_{t=j+1}^{T}\left(x_{t}-\hat{\mu}\right)^{2}\left(x_{t-j}-\hat{\mu}\right)^{2}\right\} \div\left\{\left[\sum_{t=1}^{T}\left(x_{t}-\hat{\mu}\right)^{2}\right]^{2}\right\}$

This original variance ratio test is robust under the existence of heteroscedasticity and therefore is ideal for crude oil prices. It is a model, which can offer strong results in terms of oil market efficiency and its predictability for oil market practitioners.

\subsubsection{Chow-Denning (1993)}

In comparison to Lo and MacKinlay (1988) test, which is an individual test where the null hypothesis is tested for an individual value of $k$, there is a question if stock returns are meanreverting, which will require the null hypothesis to hold for all values of $k$. Therefore, it is necessary to conduct a joint test, where a multiple comparison of VRs over a set of different time horizons is made. Under the null hypothesis, $V\left(k_{i}\right)=1$ for $i=1, \ldots, l$ against the alternative hypothesis that $V\left(k_{i}\right) \neq 1$ for some $i$. Their test statistic is as follows: 
$M V_{1}=\sqrt{T} \max _{1 \leq i \leq l}\left|M_{1}\left(x ; k_{1}\right)\right|$

where $M_{1}(x ; k)$ is defined in equation (17). The idea is that the decision regarding the null hypothesis can be based on the maximum absolute value of the individual VR statistics. The null hypothesis is rejected at a level of significance if the $M V_{1}$ statistics is greater than the 11 $\left.\left(\alpha^{*} / 2\right)\right]$ th percentile of the standard distribution, where $\alpha^{*}=1-(1-\alpha)^{1 / l}$. The heteroskedasticityrobust version of this test can be written as:

$$
M V_{2}=\sqrt{T} \max _{1 \leq i \leq l}\left|M_{2}\left(x ; k_{i}\right)\right|
$$

which is a joint test using $M_{2}(x ; k)$ given in $\{18\}$.

This multiple variance ratio test allows for multiple comparisons, which can be used to compare the outcomes with the original Lo and MacKinlay VR test.

\subsubsection{Wright (2000)}

The standard VR test is based on asymptotic approximations, which may be biased and rightskewed in finite samples, which can result in misleading inferences (Lo and MacKinlay 1989). Wright (2000) proposes to modify the standard VR test using standardised ranks and signs. This has two advantages. Firstly, as the sign and rank tests have exact sampling distribution, there is no need to resort to asymptotic approximation. Secondly, the tests may be more powerful than the conventional VR tests when the data are highly non-normal (Wright 2000). The proposed statistics are as follows:

Let $r\left(x_{t}\right)$ be the rank of $x_{t}$ among $x_{t}$ 's and consider the standardised rank $r_{1 t}=\left[r\left(x_{t}\right)\right.$ $0.5(T+1)] /[(T-1)(T+1) / 12]$. Under the null hypothesis that $x_{t}$ is generated from an iid sequence, $r\left(x_{t}\right)$ is a random permutation of the numbers of $1, \ldots, T$ with equal probability.

$R_{1}=\left(\frac{(T k)^{-1} \sum_{t=k}^{T}\left(r_{1 t}+r_{1 t-1}+\cdots+r_{1 t-k+1}\right)^{2}}{T^{-1} \sum_{t=1}^{T} r_{1 t}^{2}}\right)\left(\frac{2(2 k-1)(k-1)}{3 k T}\right)^{-1 / 2}$

$R_{2}=\left(\frac{(T k)^{-1} \sum_{t=k}^{T}\left(r_{2 t}+r_{2 t-1}+\cdots+r_{2 t-k+1}\right)^{2}}{T^{-1} \sum_{t=1}^{T} r_{2 t}^{2}}\right)\left(\frac{2(2 k-1)(k-1)}{3 k T}\right)^{-1 / 2}$

which follows an exact sampling distribution.

The modification of the traditional VR test using the ranks and signs can minimise size distortions and it is a good efficiency test to be included in the analysis for comparative reasons.

\subsubsection{Kim (2006)}

Kim (2006) offers a wild bootstrap approach to improving the small sample properties of variance ratio tests with unknown forms of conditional and unconditional heteroskedastricity. The approach involves computing the individual Lo and MacKinlay $M_{2}(k)$ and joint ChowDenning $\mathrm{MV}_{2}\left(k_{i}\right)$ VR tests on samples of $T$ observations formed by weighting the original data 
with random variables with mean of 0 and variance of 1 . The results are used to form bootstrap distributions of the test statistics.

The wild bootstrap test based on $M V_{2}\left(k_{i}\right)$ can be computed in three stages as follows:

1) Form a bootstrap sample of $T$ observations $X_{t}^{*}=\eta_{t} X_{t}(t=1, \ldots, T)$ where $\eta_{t}$ is a random sequence with $E(\eta)=0$ and $E\left(\eta^{2}\right)=1$.

2) Calculate $M V^{*}=M V_{2}\left(X^{*} ; k_{i}\right)$ statistic obtained from the bootstrap sample generated in stage 1).

3) Repeat 1) and 2) sufficiently, say $m$, times to form a bootstrap distribution of the test statistic $\left\{M V_{2}\left(X^{*} ; k_{i} ; j\right)\right\}_{j=1}^{m}$.

The $p$-value of the test can be obtained as the proportion of $\left\{M V_{2}\left(X^{*} ; k_{i} ; j\right)\right\}_{j=1}^{m}$ greater than the sample value of $M V_{2}\left(k_{i}\right)$. The wild boostrap version of $M_{2}(k)$ test can be implemented in a similar way as a two-tailed test, where we obtain $M^{*}=M_{2}\left(X^{*} ; k\right)$ in stage 2) and $\left\{M V_{2}\left(X^{*} ; k_{i} ; j\right)\right\}_{j=1}^{m}$ in stage 3$)$. Conditionally on $X_{t}, X_{t}^{*}$ is a serially uncorrelated sequence with zero mean and variance $X_{t}^{2} . M^{*}$ and $M V^{*}$ have the same asymptotic distributions as $M_{2}(k)$ and $M V_{2}\left(k_{i}\right)$ respectively. Since $X_{t}^{*}$ is a serially uncorrelated sequence, wild bootstrapping approximates the sampling distributions under the null hypothesis, which is a necessary property for a bootstrap test. Kim (2006) recommends using the standard normal distribution as other choices provide similar results. The wild bootstrapping approach is another model in efficiency testing, where a resampling method approximates the sampling distribution of a test statistics.

\subsubsection{Monte Carlo Simulation}

Charles et al., (2011) used Monte Carlo simulations to test for market efficiency based on GARCH residuals. They considered the models outlined below to support their research study.

- AR(1) model: $Y_{t}=0.1 Y_{t-1}+Z_{t}$, and $Y_{t}=0.1 Y_{t-1}+V_{t}$

- ARFIMA model: $(1-L)^{0.1} Y_{t}=Z_{t}$, and $(1-L)^{0.1} Y_{t}=V_{t}$

- The sum of a white noise and the first difference of a stationary autoregressive process of order one (NDAR): $Y_{t}=\varepsilon_{t}+X_{t}-X_{t-1}$ with $X_{t}=0.85 X_{t-1}+\mu_{t}$

where $Z_{t}=\varepsilon_{t} \mu_{t}$ with $\sigma_{t}^{2}=0.001+0.90 \sigma_{t-1}^{2}+0.09 \varepsilon_{t-1}^{2}$ (i.e. $\operatorname{GARCH}(1,1)$ errors);

$V_{t}=\exp \left(0.5 h_{t}\right) \varepsilon_{t}$ with $h_{t}=0.95 h_{t-1}+\mu_{t}$ (i.e. stochastic volatility (SV) errors); $\varepsilon_{t}$ and $\mu_{t}$ are independent i.i.d $\mathrm{N}(0,1)$. This model uses $\mathrm{GARCH}(1,1)$ residuals in the wild bootstrapping method, which offers more precise results when testing oil prices.

The key methods presented in this section are applied in the empirical part of this paper. This offers a practical view on how the outlined tests can be used by researchers and practitioners to understand the dynamics of oil markets.

\section{$4 \quad$ Data and Empirical Results}

When analysing commodity markets, where the point of interest are main crude oil benchmarks, the starting point is to choose the time period to be studied and afterwards to select the econometric models that would support the analysis and that will be capable of addressing specific research questions. As this paper combines multiple econometric methods, the selected techniques can help practitioners with decision-making processes for different time horizons as various models' results provide answers of the long term and short-term relationship 
between the benchmarks, volatility and efficiency performance. In this paper, we work on a dataset of oil spot prices around the Global Financial Crisis to demonstrate our methods. In this case, if the analyses are applied to a period after the Global Financial Crisis then the time period must be long enough to be able to establish the end of the crisis. Then the time period can be around 10 to 15 years long as the GFC ended around 2009/10. In this case, the dataset under consideration starts on 2/8/2004 and ends 31/8/2016. We use daily closing spot prices of Brent, WTI and Dubai crude oils, which are downloaded from Thomson Reuters Datastream. The study is supported by the implementation of presented research models that help examining oil prices performance during the post Global Financial Crisis period as the current market situation concerns all oil dependent businesses. To determine the end of the crisis, there is a need to apply structural break tests, which establishes the specific date, plus is very important for econometric modelling by splitting the sample to avoid spurious results. Figure 2 shows price behaviour of our variables and indicates the three major breaks identified by the Bai-Perron structural break test.

Figure 2: Historical Data and Major Break Points

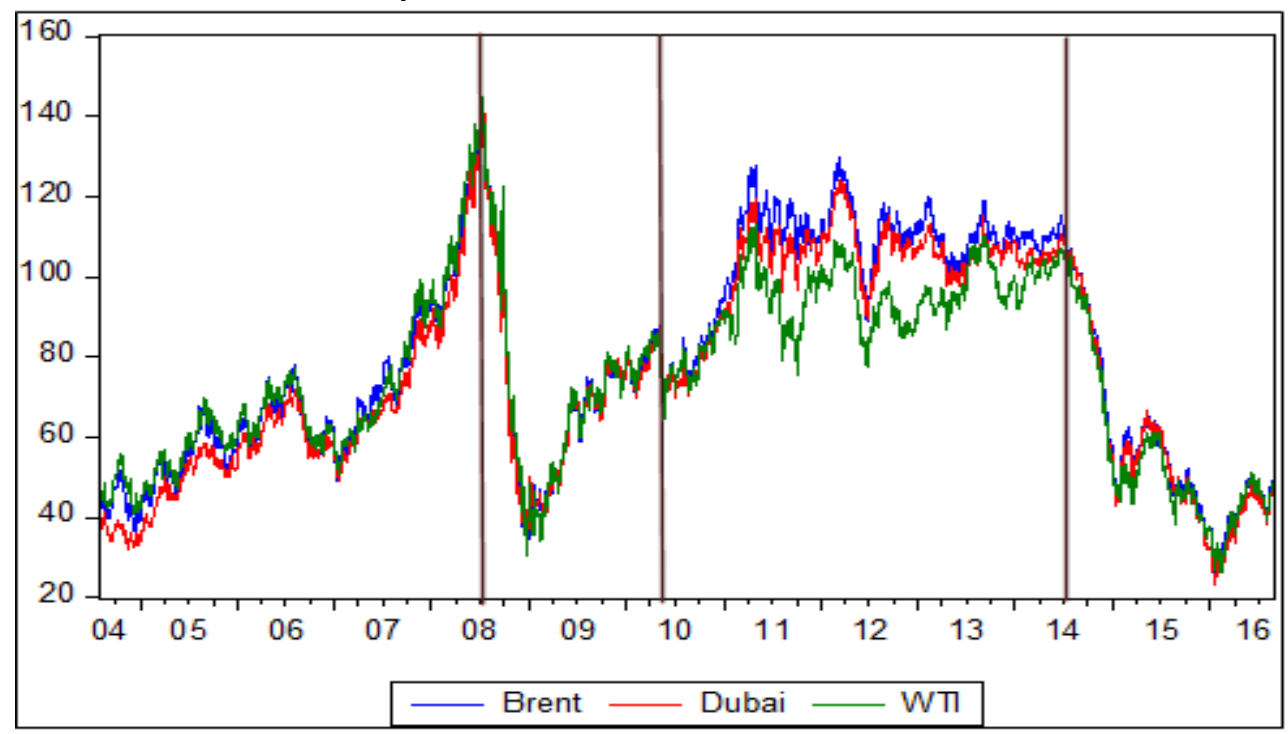

Source: Eviews Software using Datastream Oil prices, breakpoints added by the authors (2017)

Table 2 displays three main break dates identified by the Bai-Perron structural break test, also presented in Figure 2. Break one in 2008 identified the common break of the start of the Global Financial Crisis. Break two displays the end of the crisis and break three is another major break after the crisis, where there was a significant change in oil price levels. The third break is included in the further analysis as it could affect the econometric testing outcomes. This test is also applied by authors who examined the oil price behaviour (Zhang et al. (2009); Mensi et al., (2014); Morales and Andreosso-O'Callaghan (2017)).

Table 2: Bai-Perron Structural Break Point Dates

\begin{tabular}{ll}
\hline The Bai-Perron Test & \\
\hline Break 1 & $11 / 06 / 2008$ \\
Break 2 & $04 / 06 / 2010$
\end{tabular}


Break 3

$20 / 06 / 2014$

Note: Test is set to a maximum of 3 break points and $15 \%$ trimming.

Descriptive statistics show basic information of the variable prices and returns, and Table 3 displays minimum, maximum, mean, standard deviation, skewness, kurtosis, the outcome of the Jarque-Bera test for normality, and number of observations for prices and price returns. This is relevant in econometric analysis as it offers basic information of our dataset and it highlights some initial risks associated with our variables. It is a common approach followed by a significant number of researchers in the field (Salisu and Fasanya, 2013; Khediri and Charfeddine, 2015; Gu and Zhang, 2016).

Table 3: Descriptive Statistics

\begin{tabular}{lrrr|rrr}
\hline \multicolumn{3}{l}{ Sample Period 2/8/2004 to 31/8/2016 } \\
\multicolumn{3}{c}{ Prices } \\
Prices & Brent & \multicolumn{1}{c}{ WTI } & \multicolumn{1}{c}{ Dubai } & Brent & WTI & Dubai \\
\hline Mean & 79.62 & 75.41 & 76.30 & 100.03 & 100.03 & 100.03 \\
Median & 75.50 & 74.67 & 72.66 & 100.00 & 100.00 & 100.00 \\
Maximum & 143.60 & 145.31 & 141.08 & 119.68 & 117.84 & 112.37 \\
Minimum & 25.76 & 26.19 & 22.94 & 84.61 & 87.96 & 90.07 \\
Std. Dev. & 27.24 & 22.89 & 26.69 & 2.20 & 2.42 & 2.01 \\
Skewness & 0.13 & 0.13 & 0.09 & 0.37 & 0.29 & 0.17 \\
Kurtosis & 1.71 & 2.28 & 1.75 & 8.35 & 7.92 & 6.19 \\
Jarque-Bera & 225.67 & 76.38 & 210.04 & 3831.85 & 3220.78 & 1348.51 \\
Probability & 0.00 & 0.00 & 0.00 & 0.00 & 0.00 & 0.00 \\
Observations & 3153.00 & 3153.00 & 3153.00 & 3152 & 3152 & 3152 \\
\hline
\end{tabular}

The descriptive statistics in Table 3 display 3,153 observations of crude oil daily prices and 3,152 daily returns, where the minimum is $\$ 25.76$ for Brent prices, $\$ 26.19$ for WTI and $\$ 22.94$ for Dubai prices per barrel. The maximum is $\$ 143.60$, $\$ 145.31$ and $\$ 141.08$ for Brent, WTI and Dubai respectively. The standard deviation, which indicates the fluctuations of oil prices and returns, shows $27.25 \%$ for Brent, $22.89 \%$ for WTI and $26.69 \%$ for Dubai, which shows high oil price differences within the tested time period. The skewness is positive for all variables, which means that they are generally increasing over time. This is important for investors and market participants, especially for long term planning decisions and also for hedging purposes as increasing oil prices will have negative implications for oil dependant industries. Skewness and kurtosis show non-normal distribution and the Jarque-Bera test statistic also confirms this finding: outcomes that are quite common for financial data. The ADF stationarity test showed that oil prices are non-stationary in levels, but are stationary in returns, which is consistent with research conducted by Bekiros and Diks (2008) and Robe and Wallen (2016).

Figure 3 displays oil returns for Brent, WTI and Dubai crude oils. As it was established in the ADF stationarity test, oil prices are non-stationary and oil prices returns are stationary, meaning that they move around its mean and can be applied in econometric testing. This is evident in Figure 3, where all three oil returns of Brent, Dubai and WTI oscillate around the value of 100 with some jumps over the time corresponding to crises or shock periods, the Global Financial Crisis being the most apparent around year 2008/09. 
Figure 3: Crude Oil Price Returns

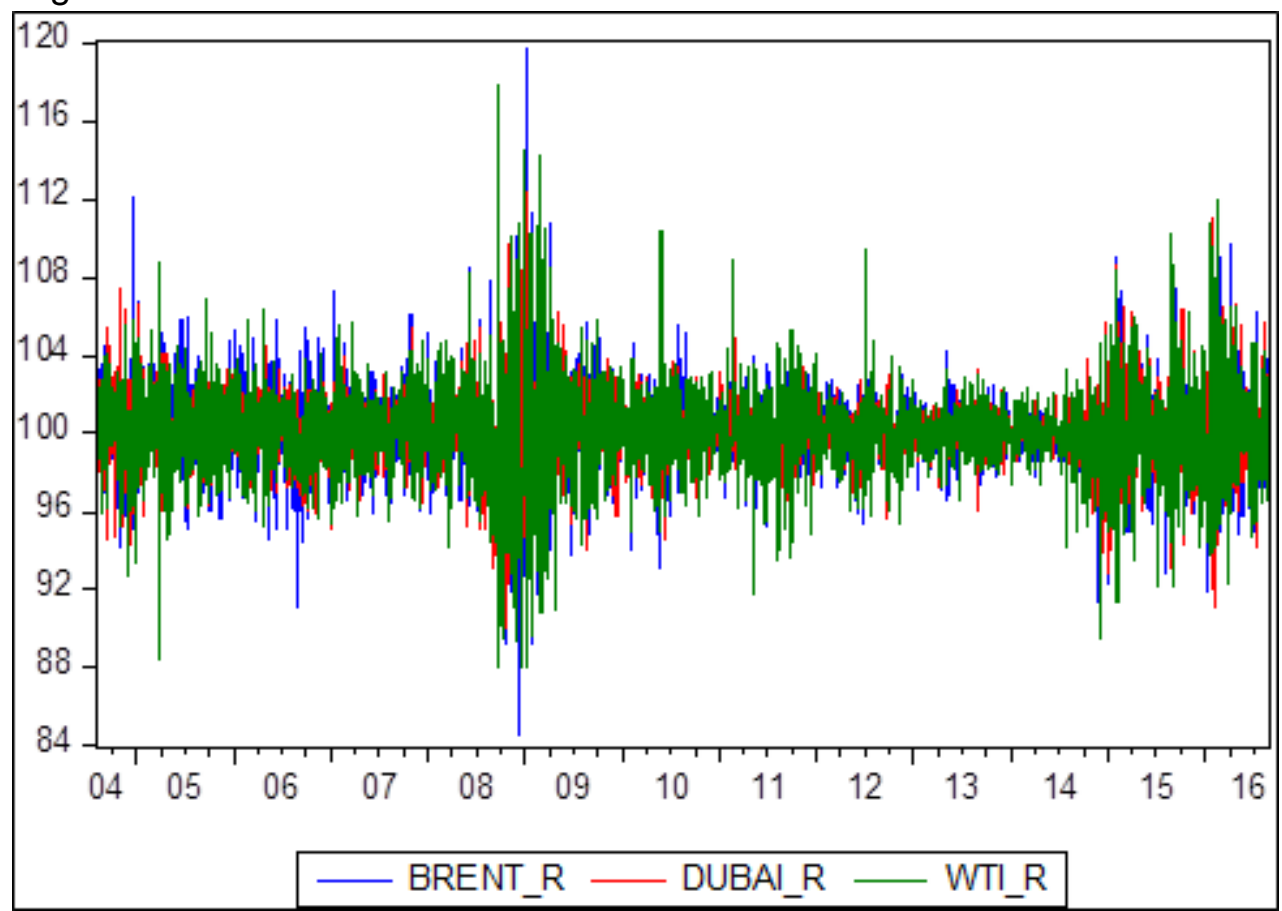

Source: Eviews Software using Datastream Oil prices (2017)

Oil price dynamics are tested with the help of the cointegration and causality tests, where cointegration analysis shows the long-term relationship and causality displays the short term relationship between variables. The outcomes in Table 4 suggest that from 2010 to 2014 there is evidence of cointegration (long-term relationship) between Brent and Dubai oil indexes, where the Johansen test displayed a presence of cointegration and the Engle-Granger test showed bidirectional cointegration. This means that these two prices move together in the long run for this time period. From 2014 to 2016, both cointegration tests exhibited bi-directional cointegration between Brent and WTI, and Brent and Dubai crude oils. These outcomes are especially important for portfolio diversification purposes, as cointegrated variables move along together in the long run and therefore are not optimal for long hedges against oil price risk.

Table 4: Cointegration Test Outcomes

\begin{tabular}{|c|c|c|}
\hline & $\begin{array}{l}\text { Johansen Cointegration } \\
\text { Test }\end{array}$ & Engle-Granger Test \\
\hline \multicolumn{3}{|c|}{$14 / 6 / 2010$ to $20 / 6 / 2014$} \\
\hline Brent and WTI & No cointegration & No cointegration \\
\hline Brent and Dubai & Cointegration & Cointegration \\
\hline WTI and Dubai & No cointegration & No cointegration \\
\hline \multicolumn{3}{|c|}{$21 / 6 / 2014$ to $31 / 8 / 2016$} \\
\hline Brent and WTI & Cointegration & Cointegration \\
\hline Brent and Dubai & Cointegration & Cointegration \\
\hline WTI and Dubai & No cointegration & No cointegration \\
\hline
\end{tabular}


The outcomes for causality are gathered with the help of the Granger causality test and the VECM model, which is applied in cases of cointegration, and the results are shown in Table 5 below.

Table 5: Causality Test Outcomes

\begin{tabular}{lll}
\hline & Granger Causality & VECM Model \\
\hline $\mathbf{1 4 / 6 / 2 0 1 0}$ to 20/6/2014 & Brent cause WTI & \\
Brent and WTI & & Brent cause Dubai \\
Brent and Dubai & WTI cause Dubai & \\
WTI and Dubai & & No causality \\
$\mathbf{2 1 / 6 / 2 0 1 4}$ to $\mathbf{3 1 / 8 / 2 0 1 6}$ & & Brent cause Dubai \\
Brent and WTI & & \\
Brent and Dubai & WTI cause Dubai & \\
WTI and Dubai &
\end{tabular}

Note: The VECM model was applied in cases of confirmed cointegration.

The results suggest the existence of a short term relationship between Brent and WTI, Brent and Dubai, and WTI and Dubai from 2010 to 2014. It also displays causal relationship between Brent and Dubai, and WTI and Dubai from 2014 to 2016. This mainly shows that Brent has a big influence on Dubai and WTI in the short term, and therefore can be taken as a leading price. Also, WTI impacts on Dubai prices in the short run indicating its importance in setting Dubai price behaviour. The main conclusion of this analysis shows that Brent is an evident crude oil price setter as it affects WTI and Dubai prices straight after the GFC period, and Brent also affects Dubai prices between 2014 and 2016. Where on the other hand, WTI affects Dubai prices between 2010 to 2014 and 2014 to 2016, but has no impact on Brent prices. This could help oil market practitioners with decision-making process when monitoring oil prices, as Brent price levels dominate over other benchmarks and offer signals for the development of the other oil market benchmarks.

The volatility analysis starts with finding the number of lags for each variable with the help of the VAR lag structure test. This is then applied in the chosen econometric models and the results are shown in table 6 . The results shown in Table 6 indicate that Dubai crude oil has higher volatility spikes $(\alpha=0.201)$ than Brent $(\alpha=0.0406)$ and WTI $(\alpha=0.411)$, but shows lower persistence, where the $\beta$ coefficient is 0.6981 for Dubai, 0.9531 for Brent and 0.9540 for WTI in the GARCH $(1,1)$ model between 2010 and 2014. This confirms that crude oil markets are very volatile even in the post-crisis period. In 2014 up to 2016, the volatility spikes increased slightly for Brent and WTI ( $\alpha=0.0435$ and 0.0758 respectively), but decreased for Dubai oil from 0.2010 to 0.0768 . The volatility persistence $(\beta)$ remained similar for Brent, slightly decreased for WTI and increased for Dubai crudes. Overall, volatility persistence is comparable for both periods. The biggest difference is found in the case of Dubai, where the volatility persistence increased from 2014 to 2016 period. From the business point of view, Brent and WTI behave in similar manner, whereas Dubai oil market exhibits higher volatility spikes, meaning that the change in oil prices is higher, but the index stabilises quicker than Brent. Therefore, the time horizon should be considered in the planning processes as the uncertainty in the oil market can last for a longer period and increase business costs through the exposure to oil price risk. 
Table 6: Volatility Results

\begin{tabular}{|c|c|c|c|c|}
\hline \multicolumn{2}{|l|}{ Volatility Models } & \multicolumn{3}{|c|}{ Period $14 / 6 / 2010$ to $20 / 6 / 2014$} \\
\hline & & Brent & WTI & Dubai \\
\hline \multirow[t]{6}{*}{ GARCH $(1,1)$} & $\boldsymbol{\omega}$ & 0.0110 & $0.0131^{*}$ & $0.1647^{\star \star \star}$ \\
\hline & & $(0.1630)$ & $(0.0952)$ & $(0.0000)$ \\
\hline & $\alpha$ & $0.0406^{\star * \star}$ & $0.0411^{* * *}$ & $0.2010^{\star \star \star}$ \\
\hline & & $(0.0000)$ & $(0.0000)$ & $(0.0000)$ \\
\hline & $\beta$ & $0.9531^{* * *}$ & $0.9540^{* * *}$ & $0.6981^{* * *}$ \\
\hline & & $(0.0000)$ & $(0.0000)$ & $(0.0000)$ \\
\hline \multirow[t]{8}{*}{ TGARCH $(1,1)$} & $\boldsymbol{\omega}$ & 0.0107 & $0.0209^{*}$ & $0.1720^{\star \star \star}$ \\
\hline & & $(0.1851)$ & $(0.0600)$ & $(0.0000)$ \\
\hline & $\alpha$ & $0.0186^{\star *}$ & $0.0128^{*}$ & $0.1434^{* * *}$ \\
\hline & & $(0.0397)$ & $(0.0975)$ & $(0.0000)$ \\
\hline & $\boldsymbol{\theta}$ & $0.0383^{\star * \star}$ & $0.0683^{\star * *}$ & $0.1110^{* *}$ \\
\hline & & $(0.0008)$ & $(0.0000)$ & $(0.0022)$ \\
\hline & $\beta$ & $0.9562^{\star \star \star}$ & $0.9445^{\star \star \star}$ & $0.6920^{\star \star \star}$ \\
\hline & & $(0.0000)$ & $(0.0000)$ & $(0.0000)$ \\
\hline
\end{tabular}

Note: ${ }^{* * *},{ }^{* *}$, ${ }^{*}$ represents statistical significance at $99 \%, 95 \%$ and $90 \%$ respectively.

\begin{tabular}{|c|c|c|c|c|}
\hline \multirow[t]{2}{*}{ Volatility Models } & \multicolumn{4}{|c|}{ Period $21 / 6 / 2014$ to $31 / 8 / 2016$} \\
\hline & & Brent & WTI & Dubai \\
\hline \multirow[t]{6}{*}{ GARCH $(1,1)$} & $\boldsymbol{\omega}$ & $0.0305^{\star \star \star}$ & $0.2255^{\star * *}$ & $0.02246^{* * *}$ \\
\hline & & $(0.0019)$ & $(0.0040)$ & $(0.0079)$ \\
\hline & $\alpha$ & $0.0435^{\star \star \star}$ & $0.0758^{* \star *}$ & $0.0768^{\star \star \star}$ \\
\hline & & $(0.0001)$ & $(0.0000)$ & $(0.0000)$ \\
\hline & $\beta$ & $0.9560^{* * *}$ & $0.8982^{* * *}$ & $0.9266^{\star * *}$ \\
\hline & & $(0.0000)$ & $(0.0000)$ & $(0.0000)$ \\
\hline \multirow[t]{8}{*}{ TGARCH $(1,1)$} & $\boldsymbol{\omega}$ & 0.0056 & $0.1429^{* * *}$ & $0.0169^{* * *}$ \\
\hline & & $(0.3005)$ & $(0.0045)$ & $(0.0000)$ \\
\hline & $\alpha$ & $-0.0182^{\star \star \star}$ & $0.0327^{\star \star}$ & $-0.0406^{\star * \star}$ \\
\hline & & $(0.0005)$ & $(0.0236)$ & $(0.0000)$ \\
\hline & $\boldsymbol{\theta}$ & $0.0934^{* * *}$ & $0.0738^{* *}$ & $0.0928^{\star * \star}$ \\
\hline & & $(0.0000)$ & $(0.0117)$ & $(0.0000)$ \\
\hline & $\beta$ & $0.9826^{\star \star \star}$ & $0.9191^{* * *}$ & $1.0028^{* \star *}$ \\
\hline & & $(0.0000)$ & $(0.0000)$ & $(0.0000)$ \\
\hline
\end{tabular}

Note: ${ }^{* \star *},{ }^{* *}$, ${ }^{*}$ represents statistical significance at $99 \%, 95 \%$ and $90 \%$ respectively.

The TGARCH $(1,1)$ model can capture leverage effects in the time series through the $\theta$ coefficient. Its results suggest that there is evidence of asymmetry in the series, where negative news has a bigger impact on oil volatility than good news (Wang and Wu, 2012; Salisu and Fasanya, 2013). This implies that a positive world economic and financial situation would have lesser impact on oil price volatility than shocks or crises. The careful consideration of shocks must be taken into account as the impact on oil prices could lead to difficulties in econometric modelling and its processes as they could affect the outcomes. 
The efficiency analysis, presented in Table 7, examining the random walk hypothesis was not confirmed in any of the variables. The application of multiple econometric models confirmed this result. Outcomes that could be interpreted as a sign of a possible arbitrage opportunity for oil market players as the future oil price level could be potentially predicted by their past price behaviour. However, some economists (Granger, 1986; Cerchi and Havenner, 1988; Engel, 1996) pointed out that prices cannot be cointegrated to be efficient. In other words, when there is no cointegration, prices are efficient. The findings in this paper show that there is evidence of cointegration, what suggests the existence of market inefficiencies. On the other hand, evidence of cointegration does not mean that oil prices are not efficient and that they do not include all available data (Dwyer and Wallace, 1992; Lence and Falk, 2005). If two prices are cointegrated, it means that they help to predict the other (Chowdhury, 1991), which would help potential hedging strategies and lower the costs to business by establishing the relationship between two variables.

Table 7: Efficiency Results

\begin{tabular}{|c|c|c|c|c|c|c|}
\hline \multirow[t]{2}{*}{ Applied Methodologies } & \multicolumn{3}{|c|}{ Period $14 / 6 / 2010$ to $20 / 6 / 2014$} & \multicolumn{3}{|c|}{ Period $21 / 6 / 2014$ to $31 / 8 / 2016$} \\
\hline & Brent & WTI & Dubai & Brent & WTI & Dubai \\
\hline Lo and MacKinlay (19988 & & & & & & \\
\hline 1989) & $X$ & $X$ & $X$ & $X$ & $X$ & $X$ \\
\hline Chow and Denning (1993) & $x$ & $x$ & $x$ & $x$ & $x$ & $x$ \\
\hline Wright (2000) & $x$ & $X$ & $X$ & $X$ & $X$ & $X$ \\
\hline Kim (2006) & $x$ & $x$ & $\mathrm{X}$ & $x$ & $x$ & $x$ \\
\hline Monte Carlo Simulation & $X$ & $X$ & $X$ & $X$ & $x$ & $X$ \\
\hline
\end{tabular}

$\sqrt{ }$ means RWH confirmed, and $X$ means RWH rejected.

The results from proposed tests bring confidence to our analysis by confirming the outcomes with the help of numerous methods.

\section{Critical Discussion}

There are significant amounts of businesses that could benefit from studies that analyse commodity markets through combining different research methodologies. Mainly, the combination of research outcomes can help with cost analysis and thus help to save business costs. Specifically, the outcomes from this paper highlight the relationship and dynamics of oil prices after the Global Financial Crisis could save considerable costs to businesses as the findings could help with future planning and cost-allocation processes. The combination of multiple methodologies brings robustness to commodity business finance. While each method has its own strengths, when combined they are capable of offering rich insights. The advantage of using both established and more recent methods gives the opportunity to analyse the outcomes of each test. This can provide better understanding of the results depending on the time frame and nature of individual test variables in different periods.

The findings in this paper show that after the Global Financial Crisis there is a strong cointegration between Brent and Dubai and Brent and WTI. This suggests that these prices impact each other in the long run and there is evidence of co-movement between the prices over time. This is consistent with findings of Mamatzakis and Remoundos (2011) that analysed oil prices between 1990 and 2009 and found evidence of long term relationship using the Engle- 
Granger cointegration test. Also, Zhang and Wang (2013) found evidence of long run relationship between oil prices using the Johansen cointegration test. This paper adds to this analysis though dividing the sample using the Bai-Perron structural break test. We found that by splitting the sample, the post Global Financial Crisis period from 2010 to 2014 showed no evidence of long term relationship between Brent and WTI, a situation that changed from 2014 to 2016, where this relationship was confirmed. This suggests that for this period prices followed the same price pattern. The findings of short run relationship show that Brent, Dubai and WTI prices display significant short run relationships, but between 2014 and 2016 there is no such relationship between Brent and WTI. The findings from existing research suggest that there is a short run relationship between oil prices at some points in time (Silvapulle and Moosa, 1999; Bekiros and Diks, 2008; Ding et al., 2014). This indicates that prices linkages are dynamic, and that businesses need to monitor oil price behaviour closely. Furthermore, these are important for portfolio diversification and hedging strategies as the co-movements at certain times should be considered for strategic purposes. This suggests that during times of confirmed price comovement between two benchmarks, the benchmarks are not a good option for hedging against oil price risk.

Another value of econometric outcomes to businesses and oil market participants are the insights brought by the volatility analysis. The differences of outcomes between Brent, Dubai and WTI suggest that volatility jumps, and persistence are similar for Brent and WTI, but quite different for Dubai crude oil. Dubai oil exhibits higher volatility jumps, meaning that its prices are subject to more fluctuations and uncertainty than in the case of Brent or WTI, but this jump or change is typically short-lived. This suggests that businesses should carefully analyse the econometric results for the oil index they predominantly use for their operations to be able to adopt an appropriate cost strategy. This analysis also highlights the difference between the benchmarks.

The efficiency outcomes did not confirm the random walk hypothesis, despite the fact that numerous efficiency tests were applied. It means that oil prices could be predicted based on past price behaviour and exhibit patterns over time helping oil market practitioners with cost analysis. This contrasts with Lean et al., (2010), Khediri and Charfedinne (2015) and Gu and Zhang (2016) who find oil markets to be efficient. However, our results are applied to post Global Financial Crisis period and are affected by the presence of cointegration, which could affect econometric modelling. Therefore, the efficiency of oil market could be confirmed under different conditions. Our mixed approach exhibits a major advantage over traditional methods by combining econometric models to indicate oil markets dynamics and oil price risks, which can reduce business costs and help with planning strategies. This is beneficial as it can explain quantitative outcomes by identifying unexpected outcomes. For example, the extant literature looking at oil price efficiency is founded on the application of well-known quantitative research methods such as the variance ratio test and $\mathrm{GARCH}$ modelling under the context of the $\mathrm{EMH}$. Therefore, the combination of different research methods provides great value for portfolio management and decision-making practices by enriching the decision-making process. Good decision making can vastly reduce the risk and save money based on good planning, which can be done with the help of focused research studies. Therefore, oil dependent businesses can benefit from these research outcomes and aim to prevent the damages that risk and uncertainty can bring to businesses. The main outcome of this study indicates that the consideration of different theories and models can support business decision-making processes, at the time that 
they help to understand the behaviour and performance of oil prices for oil dependent industries, investors, speculators and other oil market participants.

\section{Conclusions}

The integration of quantitative research methods can provide more precise outcomes, which in turn may help businesses with decision making processes. This approach may work well in many areas and commodity finance is but one of them. The combination of multiple approaches enhances the research findings and explains why variables move in certain way by capturing their behaviour and this approach brings confidence to obtained results. The combination of multiple research methodologies leads to richer insights into commodity price behaviour. Investors rely on their ability to understand variables past performance that help them to predict future trends. Using multiple methods as suggested in this paper, they can minimise their risk exposure and market uncertainty, which could have a negative impact on their business. If businesses compare outcomes from various models using specialised research, they can have more confidence when developing their strategies by being able to connect the outcomes of existing research to the issues under consideration. Therefore, integrating econometric modelling into business practices is considered as a key tool that may help oil dependent industries in sectors such as transport, airline or chemicals with decision-making practices around commodities. Future research could apply insights from the relatively new area of behavioural finance to better comprehend the interplay between the $\mathrm{EMH}$ and investment decisions thus offering additional perceptions in planning future strategies.

\section{References}

ABDMOULAH, W. (2010) Testing the evolving efficiency of Arab stock markets. International Review of Financial Analysis, 19, 25-34. https://doi.org/10.1016/j.irfa.2009.11.004

ASGHAR, Z. and ABID, I. (2007) Performance of lag length selection criteria in three different situations. MPRA Paper No. 40042. Available at: https://mpra.ub.unimuenchen.de/40042/1/MPRA_paper_40042.pdf

BAI, J. and PERRON, P. (2003) Computation and Analysis of Multiple Structural Change

Models. Journal of Applied Econometrics, 18, 1-22. https://doi.org/10.1002/jae.659

BAI, J., and PERRON, P. (1998) Estimating and Testing Linear Models with Multiple Structural Changes. Econometrica, 66, 44-78. https://doi.org/10.2307/2998540

BEKIROS, D. S., and DIKS, G. C. (2008) The relationship between crude oil spot and futures prices: Cointegration, linear and nonlinear causality. Energy Economics, 30, 2673-2685. https://doi.org/10.1016/j.eneco.2008.03.006

BOLLERSLEV, T. (1986) Generalised autoregressive conditional heteroskedasticity. Journal of Econometrics, 31, 307-327. https://doi.org/10.1016/0304-4076(86)90063-1

BOURI, E. (2015) Oil volatility shocks and the stock markets of oil-importing MENA economies: A tale from the financial crisis. Energy Economics, 51, 590-598. https://doi.org/10.1016/j.eneco.2015.09.002 
CANDELON, B., JOETS, M., and TOKPAVI, S. (2013) Testing for Granger causality in distribution tails: An application to oil markets integration. Economic Modelling, 31, 276-285. https://doi.org/10.1016/j.econmod.2012.11.049

CHARLES, A., and DARNÉ, O. (2009) Variance-ratio tests of random walk: an overview. Journal of Economic Surveys, 23, 503-527. https://doi.org/10.1111/j.1467-6419.2008.00570.x

CHARLES, A., \& DARNÉ, O. (2014). Volatility persistence in crude oil markets. Energy policy, 65, 729742. https://doi.org/10.1016/j.enpol.2013.10.042

CHARLES, A., DARNÉ, O., and Kim, J. H. (2011) Small sample properties of alternative tests for martingale difference hypothesis. Economics Letters, 110, 151-154. https://doi.org/10.1016/j.econlet.2010.11.018

$\mathrm{CHOI}$, I. (1999) Testing the random walk hypothesis for real exchange rates. Journal of Applied Econometrics, 14, 293-308. https://doi.org/10.1002/(SICl)1099-1255(199905/06)14:3<293::AIDJAE503>3.0.CO;2-5

CHOW, G. (1960) Tests of Equality between Sets of Coefficients in Two Linear Regressions. Econometrica, 28, 591-605. https://doi.org/10.2307/1910133

CHOW, K. V., and DENNING, K. C. (1993) A simple multiple variance ratio test. Journal of Econometrics, 58(3), 385-401. https://doi.org/10.1016/0304-4076(93)90051-6

CHOWDHURY, A. R. (1991). Futures market efficiency: evidence from cointegration tests. Journal of Futures markets, 11(5), 577-589. https://doi.org/10.1002/fut.3990110506

DICKEY, D., and FULLER, W. (1979) Distribution of Estimators for Time Series Regressions with a Unit Root. Journal of the American Statistical Association, 74, 427-431.

DING, H., KIM, H-G., and PARK, Y. S. (2014) Do net positions in the futures market cause spot prices in crude oil? Economic Modelling, 41, 177-190. https://doi.org/10.1016/j.econmod.2014.05.008

DWYER, G. P., \& WALLACE, M. S. (1992). Cointegration and market efficiency. Journal of International Money and Finance, 11(4), 318-327. https://doi.org/10.1016/0261-5606(92)90027-U

ENGEL, C. (1996). A note on cointegration and international capital market efficiency. Journal of International Money and Finance, 15(4), 657-660. https://doi.org/10.1016/0261-5606(96)00028-9

ENGLE, R. F. (1982) Autoregrresive conditional heteroskedasticity with estimates of the variance of United Kingdom inflation. Econometrica, 50, 987-1007. https://doi.org/10.2307/1912773

ENGLE, R. F., and GRANGER, C. W. (1987) Cointegration, and error correction: representation, estimation and testing. Econometrica, 55, 251-276. https://doi.org/10.2307/1913236

FAMA, E. F. (1965). The behavior of stock-market prices. The Journal of Business, 38, 34-105. https://doi.org/10.1086/294743

GRANGER, C. W. (1969) Investigating causal relations by econometric models and cross-spectral methods. Econometrica, 37, 424-438. https://doi.org/10.2307/1912791 
GRANGER, C. W. (1986). Developments in the study of cointegrated economic variables. Oxford Bulletin of Economics and Statistics, 48(3), 213-228. https://doi.org/10.1111/j.14680084.1986.mp48003002.x

GU, R., \& ZHANG, B. (2016). Is efficiency of crude oil market affected by multifractality? Evidence from the WTI crude oil market. Energy Economics, 53, 151-158. https://doi.org/10.1016/j.eneco.2014.10.014

HANSEN, E. B. (2001) The New Econometrics of Structural Change: Dating Breaks in U.S. Labor Productivity. Journal of Economic Perspectives, 15, 117-128. https://doi.org/10.1257/jep.15.4.117

HOQUE, H. A., KIM, J. H., and PYUN, C. S. (2007) A comparison of variance ratio tests of random walk: A case of Asian emerging stock markets. International Review of Economics \& Finance, 16, 488502. https://doi.org/10.1016/j.iref.2006.01.001

JOHANSEN, S. (1988) Statistical Analysis of Cointegration Vectors. Journal of Economics Dynamics and Control, 12, 231-254. https://doi.org/10.1016/0165-1889(88)90041-3

JOHANSON, L. L. (1960) The theory of hedging and speculation in commodity futures. The Review of Economic Studies, 27, 139-151. https://doi.org/10.2307/2296076

KHEDIRI, K. B., \& CHARFEDDINE, L. (2015). Evolving efficiency of spot and futures energy markets: A rolling sample approach. Journal of Behavioral and Experimental Finance, 6, 67-79. https://doi.org/10.1016/j.jbef.2015.03.006

KIM, J. H. (2006) Wild bootstrapping variance ratio tests. Economics Letters, 92, 38-43. https://doi.org/10.1016/j.econlet.2006.01.007

KIM, J. H. (2009) Automatic variance ratio test under conditional heteroskedasticity. Finance Research Letters, 6(3), 179-185. https://doi.org/10.1016/j.frl.2009.04.003

LEAN, H. H., MCALEER, M., \& WONG, W. K. (2010). Market efficiency of oil spot and futures: A meanvariance and stochastic dominance approach. Energy Economics, 32, 979-986. https://doi.org/10.1016/j.eneco.2010.05.001

LEE, Y-H. , HU, H-N. \& CHIOU, J-S. (2010). Jump dynamics with structural breaks for crude oil prices. Energy Economics, 32, 343-350. https://doi.org/10.1016/j.eneco.2009.08.006

LEE, J., LIST, J. A., and STRAZICICH, M. (2006) Non-renewable resource prices: deterministic or stochastic trends? Journal of Environmental Economics and Management, 51, 354-370. https://doi.org/10.1016/j.jeem.2005.09.005

LEE, C-C.. and ZENG, J-H. (2011) Revisiting the relationship between spot and futures oil prices: evidence from quantile cointegrating regression. Energy Economics, 33, 924-935. https://doi.org/10.1016/j.eneco.2011.02.012

LENCE, S., \& FALK, B. (2005). Cointegration, market integration, and market efficiency. Journal of International Money and Finance, 24(6), 873-890. https://doi.org/10.1016/j.jimonfin.2005.05.002 
LIU, C. Y., and HE, J. (1991) A Variance-Ratio Test of Random Walks in Foreign Exchange Rates. The Journal of Finance, 46, 773-785. https://doi.org/10.1111/j.1540-6261.1991.tb02686.x

LO, A., (2004) The Adaptive Markets Hypothesis: Market efficiency from an Evolutionary Perspective. Journal of Portfolio Management, 30, 15-29. https://doi.org/10.3905/jpm.2004.442611

LO, A.W. and MACKINLAY, A.C. (1988) Stock market prices do not follow random walk: Evidence from a simple specification test. Review of Financial Studies, 1, 41-66. https://doi.org/10.1093/rfs/1.1.41

Lo, A.W. and MACKINLAY, A.C. (1989) The size and power of the variance ratio test in finite sample: A Monte Carlo investigation. Journal of Econometrics, 40, 203-238. https://doi.org/10.1016/03044076(89)90083-3

MAMATZAKIS, E., and REMOUNDOS, P. (2011) Testing for adjustment costs and regime shifts in Brent crude futures market. Economic Modelling, 28, 1000-1008. https://doi.org/10.1016/j.econmod.2010.11.008

MEHRARA, M., and HAMLDAR, M. (2014) The relationship between spot and future prices in Brent crude oil market. International Letters of Social and Humanistic Sciences, 28, 15-19. https://doi.org/10.18052/www.scipress.com/ILSHS.39.15

MENSI, W., HAMMOUDEH, S., and YOON, -M. S. (2014) How do OPEC news and structural breaks impact returns and volatility in crude oil markets? Further evidence from a long memory process. Energy Economics, 42, 343-354. https://doi.org/10.1016/j.eneco.2013.11.005

MORALES, L., \& ANDREOSSO-O'CALLAGHAN, B. (2017). Volatility in Agricultural Commodity and Oil Markets during Times of Crises. Economics, Management and Financial Markets, 12, 59-82. https://doi.org/10.22381/EMFM12420173

NARAYAN, P.K. and NARAYAN, S. (2007) Modelling oil price volatility. Energy Policy, 35, 6549-6553. https://doi.org/10.1016/j.enpol.2007.07.020

NARAYAN, P. K., NARAYAN, S., and SHARMA, S. S. (2013) An analysis of commodity markets: what gain for investors? Journal of Banking \& Finance, 37(10), 3878-3889. https://doi.org/10.1016/j.jbankfin.2013.07.009

OZDEMIR, A. Z., GOKMENOGLU, K., \& EKINCI, C. (2013). Persistence in crude oil spot and futures prices. Energy, 59, 29-37. https://doi.org/10.1016/j.energy.2013.06.008

ROBE, M. \& WALLEN, J. (2016). Fundamentals, Derivatives Market Information and Oil Price Volatility. The Journal of Futures Markets, 36, 317-344. https://doi.org/10.1002/fut.21732

SADORSKY, P. (2012). Correlations and volatility spillovers between oil prices and the stock prices of clean energy and technology companies. Energy Economics, 34, 248-255. https://doi.org/10.1016/j.eneco.2011.03.006

SALISU, A. A., \& FASANYA, I. O. (2013) Modelling oil price volatility with structural breaks. Energy Policy, 52, 554-562. https://doi.org/10.1016/j.enpol.2012.10.003 
SILVAPULLE, P., \& MOOSA, I. A. (1999). The relationship between spot and futures prices: evidence from the crude oil market. The Journal of Futures Markets, 19, 175-193. https://doi.org/10.1002/(SICI)1096-9934(199904)19:2<175::AID-FUT3>3.0.CO;2-H

QUANDT, R. E. (1960) Tests of the hypothesis that a linear regression system obeys two separate regimes. Journal of the American Statistical Association, 55, 324-330. https://doi.org/10.1080/01621459.1960.10482067

WANG, Y. \& WU, C. (2012). Forecasting energy market volatility using GARCH models: Can multivariate models beat univariate models? Energy Economics, 34, 2167-2181. https://doi.org/10.1016/j.eneco.2012.03.010

WANG, Y., and WU, C. (2013) Are crude oil spot and futures prices cointegrated? Not always! Economic Modelling, 33, 641-650. https://doi.org/10.1016/j.econmod.2013.05.013

WANG, Y., WU, C. \& YANG, L. (2016). Forecasting crude oil market volatility: A Markov switching multifractal volatility approach. International Journal of Forecasting, 32, 1-9. https://doi.org/10.1016/j.ijforecast.2015.02.006

WRIGHT, J.H. (2000) Alternative variance-ratio tests using ranks and signs. Journal of Business and Economic Statistics, 18, 1-9.

ZAKOIAN, J.M. (1994) Threshold heteroskedasticity models. Journal of Economic Dynamics and Control. 18, 931-944. https://doi.org/10.1016/0165-1889(94)90039-6

ZIVOT, E., \& ANDREWS, D. (1992). Further evidence of the great crash, the oil-price shock and unit root hypothesis. Journal of Business and Economic Statistics, 11, 251-270.

ZHANG, X., LEAN, Y., WANG, S. \& LAI, K. K. (2009). Estimating the impact of extreme events on crude oil price: An EMD based event analysis method. Energy Economics, 31, 768-778. https://doi.org/10.1016/j.eneco.2009.04.003

ZHANG, Y-J., and WANG, Z-Y. (2013) Investigating the price discovery and risk transfer functions in the crude oil and gasoline futures markets: Some empirical evidence. Applied Energy, 104, 220-228. https://doi.org/10.1016/j.apenergy.2012.10.066 